\title{
Tahsin Al-Qur'an dalam Meningkatkan Spiritual well-Being Remaja dengan Perilaku Delinkuen
}

\section{Tahsin Al-Qur'an In Increasing Adolescent Spiritual Well-Being With Delinkuen Behavior}

\author{
Ati Kusmawati ${ }^{1}$, Cholichul Hadi ${ }^{2}$, Nur Ainy Fardana N2 \\ Universitas Muhammadiyah Jakarta ${ }^{1}$, Universitas Airlangga Surabaya ${ }^{2}$ \\ ati2051976@gmail.com
}

\begin{abstract}
Abstrak
Penelitian ini menguji bagaimana proses tahsin Al-Qur'an dapat meningkatkan spiritual wellbeingremaja dengan perilaku delinkuen. Metode yang digunakan ekperimental (The one shot case study). Hasil penelitian ini dapat disimpulkan dengan treatment membaca Al-Qur'an secara rutin melalui pendampingan yang intensif dan pendekatan persuasive kepada siswa dengan perilaku delinkuen dapat membawa perubahan perilaku menjadi lebih baik secara bertahap, dan disertai penjelasan dari makna atau arti ayat-ayat yang dibaca. Dukungan yang positif (parenting di sekolah) dan memberikan perhatian ekstra kepada siswa dengan perilaku delinkuen dari sekolah, guru dan orang tua akan memberikan perubahan yang baik khususnya dalam proses belajar.
\end{abstract}

Kata kunci: Tahsin Al-Qur'an, spiritual well-being, remaja, perilaku delinkuen

\begin{abstract}
This research examined how tahsin Al-Qur'an process could improve the spiritual well-being of adolescent with delinquent behavior. The method that was used was experimental (The one shot case study). The result of this research could be concluded with the treatment of reciting Al-Qur'an routinely through intensive guidance and persuasive approach to the students with delinquent behavior could bring behavior change for the better gradually, and accompanied by the explanation of the meaning of the verses that were being read. Positive support (parenting in school) and giving extra attention to students with delinquent behavior from school, teachers and parents would bring a good change especially in the learning process.
\end{abstract}

Keyword: Tahsin Al-Qur'an, spiritual well-being, adolescent, delinquent behavior 


\section{Pendahuluan}

Tahun 2018 yang baru-baru ini, tepatnya Kamis, 1 Februari 2018, adalah Ahmad Budi Cahyono (guru tidak tetap bidang seni rupa) di SMA1 Torjun Sampang, salah seorang siswanya kelas XI berinisial MHL berani membunuh lantaran ditegur oleh sang guru dan siswa ini dengan marah dan berangnya menghajar Guru Budi di depan teman-temannya meskipun ada peleraian dari teman sekelas namun nyawa Guru Budi tak tertolong lagi. Peristiwa ini tidak bisa dibiarkan, ini menambah catatan hitam dunia pendidikan Indonesia. (www.tribunnews.com, 3 Februari 2018). Peristiwa seorang siswa berani marah, memukul sampai menghilangkan nyawa orang lain dan ini adalah gurunya sendiri ketika menegur di kelas dengan cara yang kemungkinan sudah dianggap harus dilakukan pencoretan cat air di wajah siswa karena kondisi siswa yang sulit diatur, perilaku siswa tersebut merupakan perilaku delinkuen di sekolah.

Peristiwa di atas menjadi perhatian bersama. Jika dilihat dari penjelasan menurut UndangUndang R.I Nomor 20 Tahun 2003 tentang Sistem Pendidikan Nasional yaitu pendidikan adalah usaha sadar dan terencana untuk mewujudkan suasana belajar dan proses pembelajaran agar peserta didik secara aktif mengembangkan potensi dirinya untuk memiliki kekuatan spiritual keagamaan, pengendalian diri, kepribadian, kecerdasan, akhlak mulia, serta keterampilan yang diperlukan dirinya, masyarakat, bangsa dan negara.

Semua ini menjadi tugas bersama bagi sekolah, keluarga dan masyarakat. Penulis tertarik untuk mengkaji melalui penelitian tahsin al-Qur'an dalam meningkatkan spiritual well-being remaja dengan perilaku delinkuen. Adapun penulis ingin mendapatkan hasil bagaimana melalui tahsin $\mathrm{Al}^{-}$ Qur'an dalam meningkatkan spiritual well-being remaja dengan perilaku delinkuen.

Masa remaja sebagai masa transisi juga menimbulkan masa krisis yang merupakan suatu developmental challenges yang ditandai dengan kecenderungan munculnya perilaku menyimpang itu akan menjadi perilaku mengganggu (Ekowarni, 1993). Kondisi tersebut jika dilihat apabila didukung oleh lingkungan yang kurang kondusif dan sifat kepribadian yang kurang baik akan menjadi pemicu timbulnya berbagai penyimpangan perilaku dan perbuatan-perbuatan negatif yang melanggar aturan dan norma yang ada di masyarakat bahkan melanggar hukum, yang biasanya disebut dengan perilaku delinkuen. Nilai-nilai spiritual keagamaan dan akhlak mulia sangat mempengaruhi pembentukan generasi bangsa yang mampu memajukan dan menjaga bangsa Indonesia. Nilai-nilai spiritual keagamaan ini menjadi penguatan yang mendorong terwujudnya visi dan misi pendidikan nasional.

Peristiwa di atas menjadi keprihatinan bagi semua. Qaimi (2004) hasil penelitiannya bahwa kenakalan remaja diwujudkan melalui perilaku agresif dan sikap kasar, tidak suka, menolak, dan membantah perintah orangtua. Kenakalan anak berhubungan erat dengan tingkat emosinya yang dapat tergolong atas kenakalan wajar dan tidak wajar. Namun penelitian ini menunjukkan bahwa perilaku agresif berpengaruh negative terhadap pencapaian nilai pelajaran. Akhirnya, diketahui bahwa perilaku kenakalan juga berpengaruh negatif terhadap pencapaian nilai-nilai sekolah. Berkaitan dengan kenakalan siswa di sekolah menunjukkan bahwa perilaku kenakalan pelajar dipengaruhi secara langsung maupun tidak langsung oleh kedua variabel terdahulu, yaitu komunikasi orangtua dan remaja yang rendah, dan ketertarikan teman yang tinggi, ditambah dengan pengaruh langsung dari perilaku agresif pelajar itu sendiri.

Lanza, dkk. (2014), dalam penelitiannya menjelaskan kenakalan dan kejahatan sering dihubungkan dengan efek domino yang ditimbulkan seperti penyalahgunaan obat-obatan dan minum minuman keras, masalah kesehatan jiwa, dan sikap antisosial yang parah. Tindakan pencegahan yang dilakukan meliputi lima aspek yang saling mendukung, yaitu: komunitas, sekolah, keluarga, teman, dan diri sendiri. Selain itu, terdapat pula pertanyaan tentang penggunaan zat-zat terlarang dan kenakalan yang pernah dilakukan. Penilaian dalam menentukan tingkat kenakalan yang dilakukan adalah dengan mengajukan beberapa pertanyaan, seperti: (1) pernah diskros dari sekolah, (2) menjual 
obat-obatan terlarang, (3) mencuri atau pernah mencoba untuk mencuri kendaraan bermotor, (4) pernah ditangkap, (5) menyerang seseorang dengan tujuan sengaja mencelakai, (6) pernah mabuk atau teler di sekolah.

Dapat disimpulkan bahwa semua harus memiliki peran dan perhatian yang lebih bagi siswa dengan perilaku delinkuen di sekolah. Kepala sekolah dibantu oleh guru bimbingan konseling, wali kelas, guru-guru bidang studi, orang tua siswa, masyarakat setempat di lingkungan sekolah berada. Ini menjadi sinergi yang baik jika berjalan dengan baik. Karena siswa dengan perilaku delinkuen di sekolah perlu mendapatkan perhatian dari sekolah, guru, dan keluarga karena jika dibiarkan akan mengganggu proses pembelajaran dan siswa lainnya.

Berkaitan dengan siswa dengan perilaku delinkuen, maka dapat didefinisikan oleh Bridges (1927) perilaku delinkuen adalah ketidaksanggupan dalam menyesuaikan diri secara sosial dalam diri individu pada situasi yang sulit sekalipun. Faktor-faktor yang dapat membuat ini masuk ke dalam situasi sulit, bersamaan dengan mental dan kondisi fisik yang mempengaruhi kapasitas atau kemampuan individu dalam menyesuaikan diri, ini merupakan penyebab kenakalan. Kenakalan adalah suatu bentuk perilaku anti sosial meskipun tidak selalu mengacu pada perilaku ilegal, sebagian besar perilaku nakal berada pada kondisi tidak sesuai dengan norma-norma dan nilai-nilai sosial (Gyansah, dkk., 2015).

Braithwaite (1978) menyatakan bahwa perilaku kenakalan secara individual adalah kemungkinan besar mereduksi tindakan untuk menghindari pengabaian/perusakan di sekolah, menjalankan keseimbangan kekuatan dalam meninggalkan bagian masalah-masalah ekonomi dan unsur pada struktur pendidikan yang merubah individual tidak mewujudkan secara keseluruhan penurunan dalam tingkatan perilaku kenakalan. Pertama tujuan pencapaian penelitian adalah memperbaiki dan memberikan arahan dari penelitian melalui evaluasi yang berpengaruh pada perilaku kenakalan yang terestrukturisasi pada sekolah-sekolah seperti adanya pengabaian pada struktur sosial. Status sosial ekonomi menjadi penting sebagai sumber yang kurang terperhatikan sehingga adanya ketidakberhasilan. Sebab terdapat akumulasi didukung adanya bukti-bukti yang terlihat oleh anak-anak dari latar belakang sosial ekonomi yang tinggi memiliki tingkatan perilaku delinkuen yang rendah (Braithwaite, 1976). Dapat disimpulkan bahwa remaja dengan perilaku delinkuen memiliki ketidakseimbangan dalam menjalani tugas perkembangannya. Di samping tidak mampu menyesuaikan diri, kurangnya dukungan sosial dari keluarga dan ketidakberdayaan keluarga dalam menjalani tugas dan fungsinya menghadapi perkembangan anak. Sehingga anak tumbuh sesuai dengan keingiannya. Berkaitan dengan kondisi secara pribadi yang labil, akhirnya terjerumus pada narkoba, seks bebas, minuman keras, mencuri, melawan guru, tidak mau sekolah, melanggar aturan sekolah dan akhirnya putus sekolah. Mereka lebih suka untuk mencoba obat-obatan terlarang, alkohol, melakukan seks bebas yang menyebabkan kerugian pada orang tua dan guru (Brandt, 2006).

Hurlock (1973) menegaskan perilaku delikuen adalah seseorang yang melakukan tindakan pelanggaran hukum sehingga akan dioenjarakan apabila orang tersebut adalah orang dewasa. Dalam kehidupan sehari-hari, istilah delikuen dipahami untuk menyebut perilaku pelanggaran aturan atau perundang-undangan oleh remaja. Pengertian perilaku delikuen atau juvenile delinquency yang dikemukakan oleh para ahli sangat beragam. Graham (dalam Lerner, R. M., \& Laurence, S., 2004), kenakalan terjadi akibat ketidaksanggupan sekolah dalam menangani tingkat kenakalan, yang mana tingginya kenakalan disebabkan oleh ketidakpercayaan antara guru dan siswa, rendahnya komitmen terhadap sekolah oleh siswa, dan peraturan yang tidak jelas dan tidak konsisten. Berkaitan dengan prestasi dan IQ siswa delinkuen, Moffitt (dalam Lerner, R. M., \& Laurence, S., 2004), menjelaskan bahwa IQ rendah dan prestasi sekolah rendah merupakan predictor penting pada gangguan perilaku (CD), perilaku delinkuen, dan remaja dengan perilaku anti sosial.

Para pelaku delinkuen merupakan bentukan sub-budaya terpisah dan memberlakukan sistem tata nilai masyarakat luas. Ia menggambarkan sub-budaya sesuatu yang diambil dari norma-norma 
budaya yang lebih besar, namun kemudian dibelokkan secara terbalik dan berlawanan. Perilaku delinkuensi dibenarkan oleh sistem tata nilai budaya mereka, karena perilaku itu dianggap keliru oleh norma-norma budaya yang lebih besar. Menurut Johnson (dalam Haditono, 2001), perilaku delikuen remaja dibagi menjadi 2 :

a. Delinkuen sosiologis yaitu remaja memusuhi seluruh konteks social kecuali sosialnya sendiri. Kenakalan ini ditandai dengan partisipasi remaja dalam kelompok (gang) di mana hubungan remaja dengan keluarga sangat intensif serta loyalitas terhadap keluarga cukup tinggi.

b. Delikuen individu yaitu memusuhi semua orang termasuk orangtuanya sendiri. Kenakalan ini dapat berwujud dalam bentuk agresif, impulsive, dan sikap bermusuhan dengan orang lain.

Bartol, dkk. (2014) membagi kategori remaja dengan perilaku delinkuen menjadi 5 macam yaitu :

Tabel 1. Kategori Remaja Dengan Perilaku Delinkuen

\begin{tabular}{|c|c|c|}
\hline No. & Kategori perilaku delinkuen & Jenis-jenis \\
\hline 1. & Tindakan melanggar hukum terhadap orang & Kekerasan, memukul, berkelahi \\
\hline 2. & $\begin{array}{l}\text { Tindakan melanggar hukum terhadap fasilitas } \\
\text { atau barang }\end{array}$ & $\begin{array}{l}\text { Merusak milik orang lain, fasilitas } \\
\text { sekolah }\end{array}$ \\
\hline 3. & Pelanggaran terhadap narkoba & $\begin{array}{l}\text { Menggunakan dan mengedarkan } \\
\text { narkoba }\end{array}$ \\
\hline 4. & Pelanggaran terhadap ketertiban umum & Mengganggu orang lain, sulit diatur \\
\hline 5. & Pelanggaran terhadap status & Membolos, tidak disiplin, berbohong, \\
\hline
\end{tabular}

Penelitian ini lebih fokus pada bentuk-bentuk perilaku delinkuen di sekolah. Adapun perilaku delinkuen di sekolah tidak terlalu jauh dari apa yang di uraikan di atas, seperti sulit diatur, membolos, tidak disiplin, menggunakan narkoba, berbohong, merusak, mengganggu dan mencuri.

Spiritualitas sebagai "pencarian makna dalam kehidupan, aktualisasi diri dan koneksi dengan diri sendiri (inner-self), orang lain dan keseluruhannya" dan menyatakan bahwa definisi tersebut dapat diterapkan pada orang yang religius maupun yang tidak religius. Jadi spiritualitas ini cakupannya lebih universal, tidak terikat pada satu agama atau keyakinan tertentu. Namun, sampai saat ini belum disepakati definisi spiritualitas yang sifatnya umum. Robets, K.T., \& Fitzgerald, L. (1993) dalam pandangannya bahwa spiritualitas adalah membangun multidimensi yang telah didefinisikan dalam banyak cara dan umumnya dipahami terkait tetapi berbeda dari religiusitas. Keyakinan agama yang terkait dengan tradisi iman tertentu. Komitmen untuk agama mungkin melibatkan kepatuhan terhadap keyakinan tertentu (ideologi), larangan agama (seperti: menghindarialkohol, dan obat-obatan yang dilarang) dan komitmen dalam suatu ikatan keagamaan yang berusaha untuk menjadi inspirasi, hormat, kagum, bermakna, dan bertujuan bahkan pada mereka yang tidak percaya pada Tuhan. Dimensi spiritual harus selaras dengan alam semesta, berusaha untuk menjawab tentang yang tak terbatas.

Dapat disimpulkan bahwa spiritualitas merupakan konsep yang berhubungan dengan keyakinan dan nilai-nilai kehidupan individu untuk lebih baik dan bermakna dalam menjalani kehidupan baik dengan orang lain maupun lingkungannya. Penjelasan di atas masih sangat luas untuk memahami spritualitas individu maka penulis lebih spesifik dalam mengkaji terakait dengan spiritualitas individu yaitu spiritual well-being. 
Konsep spiritual well-being pada awalnya dikembangkan oleh Ellison \& Paloutzian (1983). Dengan ketercapaianya itu, dibuatlah penilaian pada spiritual well-being. Riley (1998). Berdasarkan ini,konsep agama/spiritual well-being (RSWB) dikembangkan oleh kelompok riset Klinis Interdisiplinerdi University Clinic di Graz, Austria. Itu juga hasil dari upaya untuk memperluasmodel bio-psiko-sosial (keimanan) dengan komponen agama/spiritual (Unterrainer, dkk., 2010) Spiritual wellbeingmenurut Unterrainer, dkk. (2011) yaitu sebagai kemampuan untuk memahami dan mengintegrasikan makna dan tujuan dalam keberadaan individu melaluiketerhubungan dengan diri, orang lain atau kekuatan yang lebih besar dari dirinya sendiri. Sebagai langkah pertama, adanya perbedaanantara bidang keimanan (bio-psiko-sosial) dan transenden(agama-spiritual).

Sullivan, K.D.D. (2004) dalam penelitiannya tentang hubungan antara religiusitas remaja, spiritual well-being, self-esteem dan mental illness, menjelaskan bahwa penelitian ini dirancang untuk mengeksplorasi hubungan antara agama, spiritual well-being, self esteem dan mental illness pada remaja. Hasil penelitian Achenbach, dkk., (dalam Sullivan, K.D.D., 2004). menjelaskan bahwa masa remaja terus menjadi masa transisi dan kebingungan. Banyak penelitian yang mengungkap bahwa ada peningkatan jumlah penyakit mental illness yang dapat dilihat pada kelompok usia ini. Semakin jelas kelompok mental illness pada remaja terus meningkat karena masa remaja masa yang penuh tantangan. Pada fasenya membawa kebingungan dan ketidakpastian, dengan kondisi ini, peneliti mencoba memperluas pendekatan yaitu individu-sosial, mental, fisik dan spiritual. Penelitian ini khususnya pada agama sangat berpengaruh dalam harga diri mereka. Aspek spiritual remaja dapat membantu mereka untuk mendapatkan pemahaman yang lebih baik, tidak hanya untuk dirinya sendiri, tapi juga pada lingkungan sosial mereka.

Penelitian lainnya dilakukan oleh Mirghafourvand, dkk. (2016)dengan hasil dari analisis data menunjukkan bahwa kualitas kesehatan hidup remaja putri berada sedikit di atas tingkatan cukup. Selain itu, nilai rata-rata kesejahteraan spiritual remaja putri cukup tinggi. Kualitas kesehatan hidup remaja putri berkaitan erat dengan total nilai kesejahteraan spiritual dan kedua dimensinya (kesejahteraan eksistensial dan agama). Ia juga menemukan nilai kualitas kesehatan hidup remaja putri yang lebih tinggi dari rata-rata nilai potensial tertinggi pada kuesioner dan hasil yang diperoleh sejalan dengan hasil yang didapat oleh penelitian Nik-Azin dkk. (2013) pada 276 siswa putra dan 275 siswa putri. Hasil penelitian ini sejalan dengan hasil penelitian Mazloomy, dkk. (2011) yang mengkaji hubungan antara stress kronis dan kualitas hidup yang dimiliki siswa SMA putri di Yazd, Iran.

Dapat disimpulkan bahwa remaja sebagai individu yang masih labil dan memiliki rasa ingin tahu yang tinggi, serta membutuhkan pendampingan untuk menjalani aktivitas fisik melalui kegiatan positif (seperti di sekolah) yang berhubungan dengan spiritualitas (Konopack dan McAuley, 2012) yang berefek positif pada kesehatan jiwa sehingga dapat mempengaruhi dan meningkatkan kualitas hidup seorang individu. Remaja memiliki kesempatan untuk mendapatkan kehidupan spiritual well-being dan kesehatan yang baik, ketika ketidaknyamanan dalam kehidupan tentunya spiritualitas sebagai pelindung masalah dan ketidaknyamanan serta memberikan efek positif bagi kesehatan dan hidup sehingga dapat meningkatkan kualitas hidup individu (Baheiraei, dkk. 2012).

Begitu pula remaja dengan perilaku delinkuen, mereka membutuhkan dukungan baik secara moral mapun sosial. Jika dilihat dari beberapa hasil penelitian di atas, ditegaskan bahwa remaja dalam kondisi kelabilannya membutuhkan pendampingan untuk menjalani aktivitas fisik melalui 
kegiatan positif (seperti di sekolah) yang berhubungan dengan spiritualitas yang berefek positif pada kesehatan jiwa sehingga dapat mempengaruhi dan meningkatkan kualitas hidup seorang individu.

\section{Metode Penelitian}

Subjek penelitian didapatkan melalui observasi pada Januari 2017 dan penelitian dilakukan Maret - Mei 2017 di salah satu SMP swasta di Jakarta. Usia siswa 13-15 tahun. Adapun kriteria siswa dengan perilaku delikuen diantaranya sering membolos sekolah, melangar aturan sekolah, merusak fasilitas sekolah, mengamuk dan berbicara kotor. Subjek penelitian terdiri 9 siswa. Melalui observasi dan treatment tahsin Al-qur'an yang dilakukan selama 3 bulan, siswa mendapatkan pendampingan dan pembinaan secara intensif berupa aktivitas tahsin (membaca) Al-Qur'an setiap hari (Juz ke-30) yang terdapat di dalam modul tahsin, diselingi dengan membaca terjemahan atau arti dari surat-surat tersebut, setelah treatment, diadakan diskusi berhubungan dengan nilai-nilai kehidupan sehari-hari dikaitkan dengan makna yang terdapat dalam ayat-ayat Al-Qur'an yang di bacanya. Treatment ini dilakukan selama 30 menit sebelum sekolah dimulai.

Penelitian ini menggunakan modul tahsin Al-Qur'an sebagai instrument untuk mentreatment siswa dengan perilaku delinkuen. Temuan dari penelitian ini berkaitan dengan tahsin Al-Qur'an untuk meningkatkan spiritual well-being remaja dengan perilaku delinkuen berdasarkan treatment melalui modul. Untuk penelitian ini, dilakukan treatment melalui modul tahsin dengan 9 siswa di sekolah. Metode yang digunakan dalam penelitian ini adalah eksperimen (the one shot case study). Penelitian ini disebut juga penelitian eksperimen eksploratif, maksudnya eksperimen penjelajahan yang bermaksud secara preliminer-eksploratif mencari masalah-masalah atau untuk mengembangkan hipotesis - hipotesis tentang hubungan sebab akibat sesuatu gejala. Eksperimen jenis ini hanya menggunakan binatang, benda, atau orang yang sedikit jumlahnya. Kegagalan eksperimen eksploratif tidak akan menimbulkan kerugian-kerugian sebanyak kegagalan eksperimen developmental (Hadi, 2016).

\section{Hasil Penelitian}

Dari hasil penelitian diketahui bahwa terdapat perubahan spiritual wellbeing pada siswa dengan perilaku delinkuen setelah pendampingan berupa tahsin Al-Qur'an yang disertai dengan makna dari ayat-ayat dan menggunakan bahasa yang mereka sesuai dengan usianya. Hal ini nampak pada3 siswa dari 9 siswa yang mendapatkan treatment tahsin Al-Qur'an, diketahui perubahan dirinya meliputi: (1)aktivitas mengikuti shalat berjamaah dengan guru di sekolah, (2)kurangnya agresi verbal (mengucapkan kata-kata kotor), (3)mulai mampu mengontrol emosi.

\section{Pembahasan}

Perubahan perilaku sebagai hasil treatment melalui modul tahsin untuk meningkatkan spiritual well-being remaja dengan perilaku delinkuen sebagai berikut dengan memperhatikan beberapa hal berikut:

a. Musyrif (pendamping) pada saat treatment secara intensif memberikan perlakuan sesuai dengan waktu yang ditentukan yaitu 30 menit dalam sehari sebelum masuk kelas. Hasil yang didapat pada saat awal treatment berlangsung, subyek masih memerlukan adaptasi meskipun sejak awal sebelum treatment ada penjelasan bagaimana mengikutinya.

b. Pada 1 bulan pertama siswa masih banyak yang sulit diatur, malas untuk melaksanakan treatment. Ada beberapa surat yang kurang lancar pembacaannya, seperti Al-Ma'un dan ada huruf yang masih sulit di lafalkan seperti shod, dhod, tsa, syin dan tho. 
c. Pada bulan kedua dan ketiga, siswa sudah mulai membaca surat-surat dalam modul sedikit lancar; Mampu dalam mengaplikasikan pengetahuan baru tentang makhrojul huruf dalam modul; Mengetahui hafalan surat-surat pendek; Hafalan baik namun bacaannya belum benar; Masih ada huruf-huruf yang tertukar; Sudah mampu membaca surat-surat pendek seperti : AlIkhlas, Al-Lahab dan An-Nas. Setelah membaca surat-surat pendek yang terdapat dalam modul, musyrif memberikan pembelajaran terkait dengan makna dari surat-surat pendek tersebut. Dengan tujuan agar siswa selain mampu membaca, juga mengetahui dan memahami makna yang terkandung dalam surat-surat pendek tersebut.

d. Setelah menjalani treatment selama 3 bulan, perubahan yang terjadi ada beberapa siswa yang perilakunya sedikit demi sedikit berubah, seperti sedikit bicara agresi (kotor); mulai mengikuti aturan sekolah (adanya kajian rutin setiap pagi, aktif pramuka dan berkurangnya keterlambatan masuk sekolah); bercanda tidak berlebihan dan kurangnya mengganggu teman.

Pendampingan melalui kegiatan pendekatan keagamaan (tahsin Al-Qur'an) sebelum belajar di kelas selama 30 menit meliputi:

a. Siswa dengan perilaku delinkuen mendapatkan prioritas pembinaaan melalui pendampingan tahsin Al-Qur'an yang dikhususkan pada Juz ke 30. Selain tahsin, siswa diberikan motivasi secara relaistis terkait kehidupan nyata melalui makna yang terkandung di dalam surat-surat pendek yang dibaca siswa. seperti Al-Ikhlas, An-Nass, Al-Lahab dan surat-surat lainnya pada juz ke 30. Awal siswa melaksanakan kegiatan ini masih sangat sulit dan memerlukan waktu dan kerjasama yang baik dengan guru dan Pembina siswa.

b. Guru bimbingan konseling dan agama menjadi kawan dalam hal mendengarkan keluhan dan cerita siswa dengan perilaku delinkuen ini. Dalam temuan observasi, siswa membutuhkan perhatian dan didengarkan. Dengan latar belakang yang sangat berbeda, kehidupan yang berbeda, perlakuan keluarga yang juga berbeda menjadikan siswa dengan perilaku delinkuen ini diberikan empaty agar mereka nyaman menjalani pendidikan di sekolah.

c. Pendampingan tahsin Al-Qur'an ini menjadi kegiatan rutin dan sebelumnya pihak sekolah memberitahukan kepada orangtua, terkait pembinaan dan pendampingan. Kondisinya dibuat nyaman dan enjoy agar siswa mau melaksanakan kegiatan ini.

Siswa dengan perilaku delinkuen di salah satu SMP swasta di Jakarta ini adalah memiliki perilaku yang membuat lingkungan sekolah menjadi tidak nyaman, merusak fasilitas sekolah, membolos, sering tidak mengikuti pelajaran di kelas, dan mengganggu teman di kelas. Siswa dengan perilaku delinkuen ini merupakan remaja yang sedang mencari jati diri. Hampir semua remaja mengalami masa perubahan baik fisik maupun emosi.

Pada tinjauan teori perkembangan, usia remaja adalah masa saat terjadinya perubahanperubahan yang cepat, termasuk perubahan fundamental dalam aspek kognitif, emosi, sosial dan pencapaian (Fagan, 2006). Sebagian remaja mampu mengatasi transisi ini dengan baik, namun beberapa remaja bisa jadi mengalami penurunan pada kondisi psikis, fisiologis, dan sosial. Beberapa permasalahan remaja yang muncul biasanya banyak berhubungan dengan karakteristik yang ada pada diri remaja. Hirschi's (dalam Ozbay, dkk., (2006) apa yang Dapat mencegah remaja dari tindakannya yang tidak menyenangkan. Ia melihat kenakalan atau penyimpangan sebagai sebuah tindakan yang tidak sesuai dan menjadi masalah. Ia juga mengambil salah satu sistem nilai yaitu nilai moral. Dapat disimpulkan bahwa perkembangan remaja baik secara emosi, fisik dan kognitif akan terus berproses sesuai dengan perkembangan usianya dan mencari identitas diri untuk mencapai kematangan yang lebih baik. Secara bersama-sama peran keluarga terutama orangtua, pendidik, sekolah, dan masyarakat menjadi bagian dari yang mengikuti perkembangan mereka dan terus menanamkan nilai-nilai moral agar mereka tidak terjerumus menjadi generasi yang gagal. 
Adanya perubahan pada siswa dengan perilaku delinkuen berdasarkan hasil pendampingan berupa tahsin Al-Qur'an sebaiknya disertai dengan makna dari ayat-ayat tersebut dan menggunakan bahasaa yang mereka pahami sesuai dengan usianya. Kegiatan pendampingan ini harus intensif dan memerlukan kesabaran yang sangat tinggi. Seperti disebutkan oleh Kauffman (2006) bahwa seburuk apapun siswa tunalaras (khususnya yang berperilaku delinkuen) secara nyata masih dapat direhabilitasi dengan cara yang membuat mereka menerima perlakuan yang baik. Semua ini memerlukan proses yang panjang dan adanya sinergitas yang baik untuk perubahannya.

Penelitian yang dilakukan penulis dengan metode eksperimen ekperimental (The one shot case study).Dapat disimpulkan dengan Treatment tahsin Al-Qur'an ini dapat menjadi solusi bagi sekolah yang memiliki siswa dengan perilaku delinkuen akan membawa perubahan perilaku menjadi lebih baik secara bertahap, dan disertai penjelasan dari makna atau arti ayat-ayat yang di baca. Seperti dapat dirasakan oleh sekolah dari 9 siswa yang mendapatkan treatment tahsin Al-Qur'an, terdapat 3 siswa yang perubahan dirinya dimulai dengan mengikuti shalat berjamaah dengan guru di sekilah, kurangnya agresi verbal (mengucapkan kata-kata kotor), sudah mulai mampu mengontrol emosi (yang hampir setiap hari marah dan senangnya mengganggu teman saat ini terlihat ada perubahan). Dukungan yang positif dan memberikan perhatian ekstra kepada siswa dengan perilaku delinkuen dari sekolah, guru dan orang tua akan memberikan perubahan yang baik khususnya dalam proses belajar. Selain itu, kegiatan parenting sangat diperlukan bagi perkembangan siswa dengan perilaku delikuen maupun belajarnya.

\section{Kesimpulan}

Dari hasil penelitian disimpulkan bahwa perubahan spiritual wellbeing pada siswa dengan perilaku delinkuen setelah pendampingan berupa tahsin Al-Qur'an, diketahui dari perubahan pada3 siswa dari 9 siswa yang mendapatkan treatment tahsin Al-Qur'an, diketahui perubahan dirinya meliputi: (1)aktivitas mengikuti shalat berjamaah dengan guru di sekolah, (2)kurangnya agresi verbal (mengucapkan kata-kata kotor), (3)mulai mampu mengontrol emosi. Kegiatan tahsin Al-Qur'an menjadi alternative pilihan untuk membantu perubahan sikap dan perilaku bagi siswa dengan perilaku delinkuen yang masih dapat diatasi/belum terlalu berat gangguannya. Selain itu, disarankan adanya kerjasama yang baik dan serius dari pihak sekolah kepada orangtua untuk secara rutin mengadakan pertemuan seperti parenting per tiga bulan dengan tujuan adanya evaluasi terhadap kondisi anak/siswa dengan perilaku delinkuen. Dari pihak sekolah diharapkan memberikan fasilitas yang dibutuhkan remaja dengan perilaku delinkuen. Sekolah menjadi central of change bagi remaja dengan segala kebutuhan belajar dan program parenting menjadi penting bagi sekolah untuk terus mengadakan dan berkomunikasi kepada orangtua, dengan kegiatan parenting ini menjadi wadah sekolah untuk dapat secara bersama-sama memberikan perhatian kepada remaja dengan perilaku delikuen.

\section{Daftar Pustaka}

Baheiraei, A., Mirghafourvand, M., Mohammadi, E., \& Charandabi, S. M. (2012). The experiences of women of reproductive age regarding health-promotion behaviours: a qualitative study. BMC Public Health, 12, 573.

Baheiraei, A., Mirghafourvand, M., Mohammodi, E., Mohammad- Alizadeh, C., \& Nedjat, S. (2013). Determining appropriate strategies for improving women's health promoting behaviours: using the nominal group technique. Eastern Mediterranean Health Journal, 19(5), 409-416. 
Bartol, C.R., \& A.M. B. (2014). Criminal Behavior : Psychological Approach. Pearson.

Braithwaite, J., \& Valerie B. (1978). An Exploratory study ofdelinquency and the nature of schooling. Journal of Sociology, 14 (2), 25 http://jos.sagepub.com/content/14/1/25.

Braithwaite, J.B. (1976). Inequality, Crime and Public Policy, Disertation. University of Queensland.

Brandt, D., (2006). Delinquency, Development, and Social Policy. Yale University Press. New Haven. London.

Bridges,K.M.B. (1927). Factors Contributing to Juvenile Delinquency. Journal of Criminal Law and Criminology, 17, 531.

Ekowarni, E. (1993). Kenakalan Remaja: Suatu Tinjauan Psikologi. Bulettin Psikologi: 2: 24-27.

Fagan, R. (2006). Counseling and Treating Adolescents with Alcohol and Other Substance Use Problems and their Family. The Family Journal: Counseling therapy For Couples and Families. Vol.14. No.4.326-333. Sage Publication diakses melalui http://tfj.sagepub.com/cgi/reprint/14/4/326 pada 18 April 2008

Gyansah, S.T., Rejoice, S., \& Gabriel, E. (2015). Child Delinquency And Pupils' Academic Performance In Fumesua Municipal Assembly Primary School In The Ejisujuaben Municipality, Ashanti Region, Ghana. Journal of Education and Practice, 6, 12.

Haditono, R.S. (2001).Psikologi Perkembangan.Yogyakarta : Gajahmada University Press

Hadi, S. (2016). Metodologi Riset. Yogyakarta : Pustaka Pelajar.

Hurlock, E.B. (1993). Adolescent Development. Tokyo : MC-Hill. Kogakusha, Ltd

Konopack, J. F., \& McAuley, E. (2012). Efficacy-Mediated Effects Of Spirituality And Physical Activity On Quality Of Life: A Path Analysis. Health and Quality of Life Outcomes, 10, 57.

Lanza, S.T., Brittany R. C., \& Bethany, C.B. (2014). Population Heterogeneity in The Salience of Multiple Risk Factors for Adolescent Deliquency. Journal of Adolescent Health, 54, 319-325.

Lerner, R. M., \& Laurence, S. (2004). Handbook of Adolescent Psychology. Canada : John Wiley \& Sons, Inc , New Jersey

Mazloomy, M. S., Zolghadr, R., Mirzaie, A. M., \& Hasanbaigi, A. (2011). Relationship Between Chronic Stress And Quality Of Life In Female Students In Yazd City In 2011. The Journal of Tolooebehdasht, 10(2), 1-10.

Mirghafourvand, M., Sakineh, M.A.C., Fariba, A.S., Favziye, S. (2016). Spiritual Well-Being and Health-Related Quality of Life in Iranian Adolescent Girls. Community Ment Health J. 52:484-492. DOI 10.1007/s10597-016-9988-3

Nik-Azin, A., Shairi, M., \& Nainian, M. (2013). Health Related Quality Of Life In Adolescents: Mental Health, Socio-Economic Status, Gender, And Age Differences. Developmental Pscychology, 9(35), 271-281. 
Ozbay, O., \& Yusuf, Z.O. (2006) A Test Of Hirschi's Social Bonding Theory: Juvenile Delinquency In The High Schools Of Ankara, Turkey. International Journal of Offender Therapy and Comparative Criminology, 50, 711. DOI : 10.1177/036624X05283525.

Bagus, M.G.A.P. (2017). Perempuan-Perempuan Pemburu Surga. Yogyakarta : Suara Muhammadiyah

Qaimi A. (2004). Keluarga dan Anak Bermasalah. Bogor : Penerbit Cahaya.

Riley, B. B.(1998)., Types Of Spiritual Well-Being Among Persons With Chronic Illness: Their Relation To Various Forms Of Quality Of Life. Archives of Physical Medicine and Rehabilitation, 3, $258-264$.

Roberts, K.T., Fitzgerald, L. (1991) Serenity : Caring with Perspective. Scholarly Inquiry for Nursing Practice : An International Journal, Vol.5, No.2

Sullivan, K.D.D., (2004). The Relationship Between Adolescent Religiosity, Spiritual Well-Being, Self Esteem and Mental Illness. A Dissertation : Faculty of the School of Psychology \& Counseling, Regent University.

Undang-Undang R.I.(2003) Tentang Sisdiknas \& Peraturan Pemerintah R.I. Tahun 2013 Tentang Standar Nasional Pendidikan Serta Wajib Belajar.

Unterrainer, H.F., Oliver, N., Joanna, C., \& Andreas, F. (2010). MI-RSWB 48: The Development of Multidimensional Inventory for Religious/Spiritual Well-Being. Diagnostica, 2, 82-93. (2011). Dimensions Of Religious/Spiritual Well-Being And Their Relation To Personality And Psychological Well-Being. Personality and Individual Differences, 49, 192-197.

Zainuddin, M. (2011). Metodologi Penelitian Kefarmasian dan Kesehatan.Surabaya : Airlangga University Press. 